\title{
Descentralização de políticas públicas sob a ótica neoinstitucional: uma revisão de literatura*
}

\author{
Pedro Cavalcante**
}

SumÁrio: 1. Introdução; 2. Descentralização: do que se trata?; 3. A descentralização no Brasil; 4. As instituições importam sim, mas quais e de que perspectiva?; 5. Considerações finais.

Summary: 1. Introduction; 2. Decentralization: What's It About?; 3. Decentralization in Brazil; 4. Institutions do matter, but which and under what perspective?; 5. Conclusions.

Palavras-chave: políticas públicas; descentralização; neoinstitucionalismo; metodologia.

KEY WORDs: public policies; decentralization; new institutionalism; methodology.

$\mathrm{O}$ artigo tem como finalidade desenvolver uma revisão de literatura sobre descentralização, com foco no caso brasileiro, ressaltando a importância dos pressupostos do neoinstitucionalismo na compreensão desse fenômeno. Em função das particularidades do nosso federalismo, é consenso na literatura a necessidade de se observar fatores de ordem institucional como normas constitucionais, estratégias de indução à cooperação, regras de funcionamento das relações federativas, entre outros. A frase rotineiramente utilizada nas ciências sociais é que "as instituições importam" no estudo das políticas públicas. De fato, esse postulado parece consolidado, mas os desafios do pesquisador devem direcionar-se para a identificação das instituições

\footnotetext{
* Artigo recebido em dez. 2010 e aceito em jul. 2011.

** Especialista em políticas públicas e gestão governamental do Ministério do Planejamento, Orçamento e Gestão (MPOG) e doutorando em ciência política da Universidade de Brasília (UnB). Graduado e mestre em ciência política pela UnB, com especialização em administração pública pela Escola Brasileira de Administração Pública e de Empresas da Fundação Getulio Vargas (Ebape/FGV) e em políticas públicas e gestão governamental pela Escola Nacional de Administração Pública (Enap). Endereço: Instituto de Ciência Política, Faculdade de Estudos Sociais e Aplicados — Campus Darcy Ribeiro Asa Norte - CEP 70904-970, Brasília, DF, Brasil. E-mail: cavalcante. pedro@gmail.com.
} 
e seus efeitos sobre os processos de descentralização, superando a predominância das abordagens normativas por intermédio de pesquisas metodologicamente válidas e consistentes. Nesse sentido, o artigo procura demonstrar como aspectos das três principais versões da teoria neoinstitucional podem servir como ferramenta analítica e metodológica válida na abordagem de questões centrais à temática, como as causas e os determinantes da descentralização e sua notória proliferação. O objetivo não é esgotar o tema, ao contrário, é destacar o rol de possibilidades que essa perspectiva oferece, principalmente, para o avanço das investigações de natureza positiva.

Policy decentralization under the new institutionalism approach: a literature review

The article aims to develop a literature review of decentralization, focused on the Brazilian case, emphasizing the importance of the new institutionalism assumptions in understanding this issue. Considering the specific aspects of our federalism, there is a consensus in the literature about the need to observe institutional factors such as constitutional rules, strategies to induce cooperation, federative relations rules, among others. The phrase usually mentioned in social science is that 'institutions matter' in the policy studies. Indeed, this postulate seems consolidated, however the researcher challenges should focus on identifying institutions and their effects over the decentralization process, surpassing the normative dominance through valid and consistent methodologically research. Therefore, this article outlines how assumptions of three major versions of the institutional theory fit as an analytical tool and valid methodology for analyzing crucial issues to the theme, such as the causes and determinants of decentralization and its notorious proliferation. The goal is not to exhaust the subject, instead, is to highlight the range of possibilities that this theory offers, especially for the progress of positive research.

\section{Introdução}

O artigo tem como finalidade contribuir para o debate sobre descentralização, com foco no caso brasileiro, ressaltando a importância dos pressupostos do neoinstitucionalismo na compreensão desse fenômeno. A frase rotineiramente utilizada em artigos, teses e dissertações das ciências sociais é que "as instituições importam" na compreensão do comportamento dos atores, do processo decisório e dos resultados das políticas públicas. De fato, esse postulado parece consolidado, mas os desafios dos pesquisadores consistem em identificar as instituições relevantes e escolher o método e o arcabouço teórico apropriados para investigar o objeto de estudo.

Considerando que o campo é dominado pela ênfase em fatores de ordem institucional, dadas as especificidades do federalismo e das relações intergovernamentais no Brasil, o artigo procura demonstrar que princípios das 
três principais versões da teoria neoinstitucional podem servir como uma eficaz ferramenta analítica na abordagem da descentralização.

O objetivo não é esgotar o tema, ao contrário, é destacar as possibilidades que essa perspectiva oferece, principalmente, para a superação da predominância de investigações de caráter normativo. Para tanto, são discernidos aspectos relevantes da descentralização, como evolução, resultados e problemas, bem como discute-se brevemente a literatura brasileira sobre o tema. Em seguida, o trabalho apresenta os pressupostos basilares da teoria neoinstitucionalista, sua relação com três questões relevantes da descentralização - causas, determinantes e proliferação - , enfatizando os respectivos quadros conceituais teóricos e as alternativas metodológicas aos analistas.

\section{Descentralização: do que se trata?}

Embora a temática tenha sido mais valorizada recentemente nas ciências sociais, seu debate é bem mais antigo. A descentralização compõe a discussão sobre formação do Estado desde filósofos clássicos, como Tocqueville e Madison, por exemplo. O interesse é reflexo da formação dos pesquisadores, logo, economistas tendem a focar o desenvolvimento fiscal e econômico, cientistas políticos as relações intergovernamentais, eleições e mecanismos de accountability, enquanto administradores trabalham os processos, procedimentos e estruturas institucionais.

A descentralização não é um fenômeno monolítico, pois envolve uma multiplicidade de desenhos, formas e estágios de implementação e, principalmente, é modificada de acordo com as transformações políticas, econômicas e sociais. Estratégias e pesquisas sobre descentralização, no entanto, foram intensificadas em meados do século passado e continuam em intenso processo de desenvolvimento. ${ }^{1,2}$

\footnotetext{
${ }^{1}$ De acordo com Cohen e Peterson (1996), a literatura acerca do tema pode ser dividida em três fases, cada uma com objetivos distintos: a primeira, nos anos 1960, enfatizava a descentralização como uma abordagem administrativa para o nível local de governo no âmbito da era pós-colonial; na segunda, no início da década de 1980, a estratégia voltava-se para as regiões pobres com a finalidade de ampliar a participação no processo desenvolvimentista; por fim, no período atual, a literatura foca os aspectos políticos da descentralização procurando compreender se ela, em suas diferentes formas e tipos, pode estimular a emergência da boa governança.

${ }^{2}$ Cheema e Rondinelli (2007) dividem em três fases ou ondas: i) após a Segunda Guerra Mundial e intensificada entre os anos 1960 e 1980, focada em desconcentração hierárquica das estruturas de governo e da burocracia; ii) meados da década de 1980, incluindo a repartição do poder político,
} 
A tendência de descentralização das políticas governamentais está vinculada a uma série de objetivos. De acordo com Faguet (1997), o núcleo intelectual em favor da descentralização envolve a combinação dos argumentos de eficiência alocativa e ampliação da accountability das administrações locais, enquanto aspectos relativos à diversidade, ao desenvolvimento de lideranças e à equidade são secundários. Em análise desse processo, Marcus Melo (1996) argumenta que o princípio da descentralização vem pautando as reformas do setor público nos países desenvolvidos e, posteriormente, nos emergentes, com relativo consenso acerca de sua importância e respaldo tanto em governos conservadores como em social-democratas.

A descentralização possui uma diversidade de conceituações. Atualmente, observa-se a convergência das perspectivas em torno da aproximação do conceito de governança ou governança descentralizada, devido ao aumento da interação da economia internacional e das relações entre os Estados e sociedades (Cheema e Rondinelli, 2007; Cohen e Peterson, 1996). Esse conceito não envolve apenas transferência de poder, autoridade e responsabilidade entre os níveis e esferas de governo, mas também a repartição de autoridade e recursos na modelagem das políticas públicas dentro da sociedade (World Bank, 2010; Cheema e Rondinelli, 2007), logo, a percepção de descentralização ganhou novos objetivos, racionalidade e formas.

No que tange a seus resultados, analistas defendem que os processos de descentralização podem ser responsáveis por melhorias na eficiência alocativa e equidade, ao mesmo tempo que tendem a ampliar a participação comunitária e a transparência, como muitos estudos indicam. Mas tais resultados não são uniformes entre os países e também não são poucos os casos de fracassos (Bossert, 1996; Cheema e Rondinelli, 1983, 2007; Faguet, 1997; Smoke, Gómez e Peterson, 2006). Paul Smoke e Dele Olowu (1993:1) elencam uma série de fatores que determinam o sucesso da gestão descentralizada em países africanos, porém ressaltam que: "Esses fatores são considerados necessários, mas nenhum é independente o suficiente para garantir o sucesso uma vez que é um processo de realização multidimensional e cumulativo".

Do mesmo modo, cabe salientar que a aplicação de orientações com vistas ao sucesso da descentralização não é tão simples, considerando as diferentes conjunturas e arranjos institucionais dos países (World Bank, 2010).

democratização e liberalização do mercado, expandindo o escopo decisório para o setor privado; iii) durante os anos 1990, a descentralização passou a ser vista com uma forma de abertura de governança para a participação pública mais ampla através de organizações da sociedade civil. 
Além disso, muitos acadêmicos vêm chamando a atenção para o fato de que mesmo experiências avaliadas como bem-sucedidas podem trazer efeitos colaterais e/ou riscos à gestão pública. A proliferação de práticas descentralizadas evidencia que não se trata de uma panaceia para solucionar problemas de desenvolvimento, iniquidade ou falta de participação política, na medida em que podem culminar em efeitos perversos, não apenas nos países emergentes, mas também nos desenvolvidos. Nesse sentido, a literatura é extensa na identificação dessas consequências negativas, tais como: disparidade regional e baixa qualidade na prestação dos serviços, corrupção, perda de economia de escala, danos à responsabilidade fiscal, entre outros.

Em termos gerais, os problemas não envolvem questões sobre a configuração das iniciativas e as áreas que devem ser descentralizadas, e as razões desses efeitos negativos são relacionadas à insuficiência de pré-requisitos para a implementação da descentralização, dentro de uma ação conjunta altamente complexa convergente com os contextos específicos de cada nação (Melo, 1996; World Bank, 2010; Prud'homme, 1995; Stohr, 2001).

\section{A descentralização no Brasil}

No Brasil, esse campo de estudo também é marcado pela variedade de perspectivas que, em sua maioria, focam a descentralização fiscal e as políticas sociais. O país é muitas vezes considerado o mais descentralizado do mundo (Samuels, 2004; Arretche, 2009; Abrucio, 2005), o que possui forte correlação com sua estrutura federativa particular. Com efeito, a compreensão da dinâmica das relações federativas é praticamente um pré-requisito para a análise do processo descentralizador brasileiro, tendo em vista seus impactos na divisão de responsabilidades e recursos entre os níveis de governo e, por conseguinte, no funcionamento dos programas governamentais.

A Constituição Federal de 1988 estabeleceu o sistema federativo como cláusula pétrea e introduziu a figura dos municípios como entes autônomos, fato inédito nos sistemas federalistas do mundo. Os níveis de governo - União, estados e municípios e o distrito federal, que acumula competências estaduais e municipais - possuem eleições para cargos executivos e legislativos, significativa autonomia administrativa, atribuições em distintas políticas públicas, bem como capacidade de arrecadação tributária e despesas próprias.

Teoricamente, o federalismo pode ser dividido em dois tipos: competitivo e cooperativo. O primeiro consiste na distribuição de competências entre as esferas de governo de modo a preservar a autonomia e a competição nas atri- 
buições de determinada área da política pública (Franzese e Abrucio, 2009). Um exemplo é a política tributária no Brasil, que propicia certa discricionariedade aos estados ao mesmo tempo que gera situações competitivas, como a chamada guerra fiscal. No sentido oposto, o padrão cooperativo envolve a repartição de atribuições entre os entes com vistas a atuarem conjuntamente na formulação e implementação da política (Almeida, 1996; Souza, 2005; Franzese e Abrucio, 2009). Esse modelo se aproxima do proposto para a gestão das políticas sociais no texto constitucional, que define em seu art. 23 competências comuns para União, estados e municípios em importantes áreas como da saúde, assistência social, educação e combate à pobreza, entre outras.

A despeito da postura na direção do modelo ideal de federalismo cooperativo nas principais áreas das políticas públicas, na prática, ainda prevalecem dificuldades para sua plena realização. Com efeito, observa-se um processo heterogêneo de gestão compartilhada, influenciado pela importância da temática na agenda governamental, pelo desenho de cada política específica e pela distribuição prévia de competências e do controle sobre os recursos entre as esferas de governo. Em certas áreas, optou-se pela transferência aos entes subnacionais da prerrogativa de decidir o conteúdo e o formato dos programas, enquanto em outras os governos estaduais e municipais tornaramse responsáveis pela implementação de políticas definidas em nível federal (Arretche, 2004).

Quanto às políticas sociais, a complexidade do arranjo federativo brasileiro apresenta tendências simultâneas tanto centralizadoras quanto descentralizadoras, o que não necessariamente é algo negativo, como defende Almeida (2000:1):

Não há nada de errado com o modelo federativo brasileiro, no que concerne à proteção social. A superposição de competências e atribuições está longe de ser uma distorção. Ela não só corresponde a um tipo específico de federalismo, praticado em outras partes do mundo, como também parece adequada à diversidade de situações e capacidades dos níveis subnacionais de governo no Brasil.

Em suma, a Constituição de 1988 institui um processo de descentralização dos serviços públicos básicos mediante a definição de macrorresponsabilidades. A partir de então, cada área necessitava desenvolver os mecanismos de coordenação e cooperação intergovernamental de modo a colocar em prática os pressupostos constitucionais. Não se trata de um processo automático do tipo top-down. Cada política requer uma estratégia de implementação que coordena as relações intergovernamentais, pautadas em adesão, barganhas e estratégias de indução (Arretche, 2004). 
Quanto à evolução do processo, prevalece o consenso de que as ações no sentido de estruturar a coordenação e cooperação das políticas sociais nos governos Sarney, Collor e Itamar não foram expressivas. De acordo com Falleti (2006), a primeira tentativa de descentralização após a Constituição de 1988, empreendida no governo Sarney, ficou conhecida como Operação Desmonte, marcada pela não adesão de governadores e prefeitos na medida em que a transferência de responsabilidades não era vinculada à garantia dos recursos financeiros. Diferentemente de outros países latino-americanos que iniciaram seus processos no setor da educação, no Brasil, a descentralização administrativa começou na saúde, fortemente influenciada pelo movimento sanitarista.

Apenas a partir de 1995 é possível verificar uma estratégia decisiva do governo federal no sentido de efetivar a parceria com os estados e municípios na gestão das políticas sociais (Almeida, 1996; Affonso e Silva, 1996). Nesse contexto, Melo (2005) argumenta que as mudanças na gestão do presidente Fernando Henrique Cardoso (1995-2002) ocorreram da seguinte forma:

A mudança de padrão ocorreu em vários âmbitos: reorganização estrutural das relações intergovernamentais no setor, no qual, embora tenha havido continuidade do processo de descentralização setorial, ocorreu um expressivo fortalecimento do controle exercido pelo âmbito federal; no processo orçamentário setorial que se tornou marcadamente "rígido", com amplo e significativo crescimento de despesas "vinculadas" na área social; e no aggionarmento da área social que perdeu inegavelmente vários traços clientelistas pretéritos. (Melo, 2005:845)

Desde então, a descentralização se apresenta como o princípio norteador da maioria dos processos de implementação das políticas sociais no país. As áreas da saúde e educação são os casos mais consolidados de gestão compartilhada entre as três esferas de governo, enquanto os estágios de políticas como saneamento e habitação ainda encontram-se em fase embrionária. Isto é, em boa parte, reflexo da forma como a política é executada. Arretche (2009) classifica as políticas implementadas pelos governos locais em dois tipos: i) regulada, nas quais a legislação federal define a estrutura nacional e a Constituição destina os recursos dos governos locais — saúde e educação; ii) não regulada: aquelas em que o governo local é muito menos regulado pela legislação federal — habitação, transporte e saneamento.

Ademais, outras questões também demonstram convergências na literatura de descentralização do país: primeiro, a priorização da municipalização 
dos serviços; segundo, o governo federal com papéis de coordenação e financiamento; e, por fim, o sucesso das experiências está vinculado à criação de uma estrutura de incentivos aos governos subnacionais.

A tendência de enfatizar os municípios como principais provedores de serviços públicos, e não os estados, é tanto uma inovação como uma consequência do federalismo brasileiro. A proximidade maior para obter informações sobre as preferências e necessidades da população local, bem como a magnitude do território nacional, são considerados fatores centrais na opção da execução das políticas públicas via municípios. O resultado dessa convergência é destacado por Franzese e Abrucio (2009:41):

O resultado desse panorama foi a transferência não apenas de recursos vinculados a programas, mas de grande parte da gestão das políticas sociais para o nível municipal. Esse processo produz uma nova burocracia local e novas clientelas de serviços que, ao longo do tempo, fortalecem o município no contexto federativo.

Quanto ao governo federal, este tem sido o protagonista da coordenação federativa, em função de sua posição estratégica em relação aos governos subnacionais e do papel de financiador e normatizador (Almeida, 1996; Affonso e Silva, 1996). Segundo Arretche (2009), os poderes regulatórios e de definição de gastos são bem concentrados no nível central, o que culmina no monitoramento dos governos subnacionais no que tange às finanças e à execução dos programas federais. Entretanto, o grau de importância do governo federal varia significativamente, haja vista que pode atuar de facilitador do diálogo entre os governos subnacionais a responsável exclusivo de algumas áreas da ação estatal.

Finalmente, o terceiro aspecto de convergência é a percepção de que a viabilidade das iniciativas de descentralização no Brasil se deve, principalmente, à construção de um arranjo institucional que reflita incentivos à participação efetiva, fluxo contínuo de informação e capacidade de controle e accountability. E, consequentemente, resulte no alinhamento dos interesses dos governos federal e subnacionais (Bossert, 1996; Faguet, 1997; Tendler, 1998; Arretche, 2003; Kaufman e Nelson, 2004; Nelson, 2004). Na mesma direção, o Banco Mundial (World Bank, 2010) defende que o sucesso da política depende da observância dos seguintes princípios no desenho da implementação: financiamento das funções; processo decisório bem informado; aderência a prioridades locais e accountability. 
Cabe salientar, entretanto, que o processo de descentralização no Brasil não é isento de problemas, longe disso. Autores como Abrucio (2005) e Farah e Jaco (2000) destacam que a interdependência e a heterogeneidade dos entes também acarretam uma série de problemas de coordenação e cooperação intergovernamental, tais como a descentralização tutelada e a guerra fiscal, entre outros.

Diante do exposto, é notório que a literatura, de forma geral, aborda o processo descentralizador brasileiro a partir da dinâmica das relações intergovernamentais, intensificada pelas deliberações da Constituição Federal de 1988. Consequentemente, a observância de fatores de ordem institucional como normas constitucionais, regras eleitorais e de funcionamento das relações federativas, entre outras, permeia o campo de estudo no país.

No tópico seguinte, à luz dos pressupostos da teoria neoinstitucional, são discutidas as causas, os determinantes e a proliferação da descentralização como forma de ampliar as fronteiras para pesquisas futuras.

\section{As instituições importam sim, mas quais e de que perspectiva?}

Após um período à margem da ciência política, o institucionalismo ressurge em meados da década de 1980 com o objetivo de recuperar a atenção às instituições. A nova versão, neoinstitucionalismo, nasce a partir das críticas aos movimentos behavioristas e da escolha racional, salientando as limitações destas abordagens, tais como o reducionismo - resultante da ênfase restrita ao indivíduo, do utilitarismo da pouca relevância dada à história. Entretanto, é inegável que a revolução behaviorista dos anos 1960 e 1970 trouxe sofisticação ao estudo da política, ampliando o escopo dos métodos, não se restringindo apenas à história e ao direito (Rhodes 2002). A utilização da quantificação e da análise estatística pode servir tanto para se apreciar as instituições como o comportamento político individual. A escolha racional incrementou ainda mais a análise do comportamento político de atores e grupos ao incorporar os pressupostos da racionalidade, da maximização da utilidade e da interação estratégica.

Os neoinstitucionalistas convergem no argumento de que as instituições são cruciais na análise do fenômeno social, uma vez que podem exercer forte influência na determinação do processo decisório e dos resultados políticos (Hall e Taylor, 2003). Mas o que são efetivamente instituições? Elionor Ostrom (1999) argumenta que a própria conceituação do termo instituições se apresenta como uma dificuldade à análise institucional na medida em que se 
refere a vários tipos de entidades, incluindo ao mesmo tempo as organizações e as regras usadas para estruturar as relações dentro e entre as organizações.

No entanto, a visão predominante caracteriza as instituições como formas de jogo, ou seja, constituem as regras dentro de uma sociedade que moldam a interação entre indivíduos e definem a estrutura de incentivos da sociedade (North, 1990). Ademais, numa perspectiva mais abrangente, podem incluir desde acordos formais para regular o processo decisório como também rotinas, costumes, hábitos, normas sociais e cultura (March e Olsen, 1989). Tais interpretações convergem com os desafios elencados por Ostrom (1999) de que as instituições são invisíveis, requerem padronização em função de sua abordagem multidisciplinar e também envolvem múltiplos níveis de análise.

Mas para que servem as instituições? As instituições possuem várias funções: reduzir as incertezas, introduzir regularidade e estabilidade ao dia a dia, servir de guia para as interações humanas, propagar informação, determinar as estruturas de incentivos e ajudar as pessoas a decodificar o contexto social, de forma a torná-las aptas para fazer escolhas e tomar decisões.

No campo das políticas públicas, Immergut (2006) salienta que foram justamente esses estudos que ajudaram a ressuscitar o interesse pelas instituições, uma vez que as pesquisas foram evidenciando que os resultados das políticas não poderiam se pautar somente nas preferências dos cidadãos, equilíbrio de grupo de interesses ou forças de estruturas sociais, como classes, por exemplo. Assim, proliferaram pesquisas que analisam em que medida as instituições importam na explicação da ação, processos e resultados (Weaver e Rockman, 1993; Weir, Orloff, e Skocpol, 1998; Immergut, 1996). As conclusões desses estudos corroboram a afirmação de Thelen e Steinmo (1992) de que as estruturas institucionais influenciam os resultados, embora não sejam sua única causa. Mais importante do que as características formais das instituições estatais e sociais é como a configuração institucional dada modela as interações políticas.

Apesar de convergirem no pressuposto da importância das instituições, a teoria tem sido subdividida em três versões de maior destaque: escolha racional, histórico e sociológico (Hall e Taylor, 2003). Em síntese, elas se diferenciam na forma como conceituam a relação entre instituições e comportamento e como explicam os processos de mudança e origem das instituições. Vivien Schmidt (2006:1) resume as diferenças entre elas:

O institucionalismo da escolha racional concentra-se em atores perseguindo os seus interesses e seguindo suas preferências dentro das instituições políticas, definidas como estruturas de incentivos, de acordo com uma "lógica do cálculo" 
[lógica da consequência]. O institucionalismo histórico se concentra na história das instituições políticas que têm suas origens nos resultados das escolhas propositais e condições iniciais históricas, e que se desenvolvem ao longo do tempo na sequência de path dependence. Já institucionalismo sociológico vê instituições políticas como socialmente constituídas e culturalmente moldadas, com agentes políticos agindo de acordo com a "lógica da adequação", que decorre culturalmente de regras e normas.

Cada uma dessas vertentes apresenta princípios que auxiliam na análise de questões centrais dos processos de descentralização. Dessa forma, discutem-se três temas desse campo de estudo que podem enriquecer o debate acadêmico e subsidiar o processo decisório, ressaltando as possibilidades do ponto de vista teórico e metodológico.

\subsection{Causas da descentralização}

Devido à sua relevância, a temática é uma das mais estudadas, principalmente, pelo fato de o fenômeno ser convergente em quase todos os países da América Latina. É notório que a descentralização tomou formas e níveis diversos internamente e entre os países e suas causas não refletem uma decisão única, ao contrário, envolvem um processo de negociação contínuo e de longo prazo. Com efeito, espera-se uma variedade de interpretações que reflitam as estruturas políticas e institucionais de cada nação, tais como o tipo de Estado, unitário ou federal, a força dos governos subnacionais, bem como as relações entre os poderes e a sociedade civil.

Na análise da América Latina, Kaufman e Nelson (2004) destacam que as legislaturas e os partidos foram importantes em alguns casos, mas desempenharam um papel menos proeminente que o Executivo, até mesmo na fase de autorização. Além disso, as principais explicações para o fenômeno englobam fatores institucionais como regras eleitorais, variáveis econômicas - crise fiscal ou taxa de crescimento econômico - , pressões externas e demandas da sociedade civil (Gonzalez, 2008). Morris e Lowder (1992) defendem que os esforços dos governos visaram reduzir os efeitos cumulativos de séculos de centralismo e que as tendências de democratização e de aumento da participação são as causas e consequências da descentralização na região. Todavia, não há consenso acerca do tema, como fica claro nas conclusões de Montero e Samuels (2004:29): 
Os fatores históricos, institucionais e socioeconômicos importam; como exemplo, a emergência da municipalização do Brasil trouxe efeitos distintos da fraca demanda dos municípios no Chile. Mas a democratização e reformas neoliberais não são suficientes e nem necessárias explicações para a descentralização. Finalmente, as abordagens institucionais e eleitorais, suplementada com análise de fatores macro, oferecem as melhores condições para a compreensão do fenômeno.

De acordo com os autores, a descentralização não é resultado simples das diferentes demandas locais por serviços, das distintas capacidades de arrecadação ou administração de programas, ou da variação de visão tecnocrata sobre a fórmula correta. As escolhas e instituições políticas desempenharam um papel central na explicação da forma, grau e sucesso da descentralização na América Latina.

No caso brasileiro, Almeida (2005) afirma que nos debates da Assembleia Constituinte a defesa da descentralização de responsabilidades se explicava como uma forma de ampliação da democracia, da eficiência e eficácia das ações do governo. Aliado à aversão ao centralismo burocrático das ações governamentais vigente durante os governos militares e ao consenso de que a extensão do território nacional requeria iniciativas conjuntas e pautadas no conhecimento das particularidades de cada região, os constituintes optaram pelo formato das competências concorrentes e de gestão compartilhada com os governos estaduais e municipais, principalmente nas políticas sociais.

Por outro lado, Samuels (2004) discorda da hipótese de que a democratização levou à descentralização, uma vez que essa última é anterior no Brasil. O autor concorda com o argumento geográfico, mas ressalta que ele foi utilizado ainda no governo militar, e acrescenta que a dinâmica política/eleitoral e o consenso partidário acerca da importância da descentralização se impuseram sobre a resistência da burocracia federal.

As abordagens são bastante diversificadas, mas convergem entre si na medida em que requerem argumentos temporais e atenção para os contextos e configurações históricas na análise desse processo de mudança, aproximandose do neoinstitucionalismo histórico.

Assim como as outras vertentes, os históricos também argumentam que as rotinas organizadas exercem um papel crucial na alocação de recursos e na estruturação de incentivos, opções e restrições encaradas pelos participantes políticos. Entretanto, Thelen e Steinmo (1992) destacam que a vertente histórica avança nessa argumentação na medida em que as instituições desempenham um papel maior do que apenas modelar a política. 
Nesse sentido, o neoinstitucionalismo histórico se direciona para o dinamismo, haja vista sua preocupação com a investigação do surgimento e do declínio de instituições, buscando suas origens, impactos e estabilidade ou instabilidade de instituições específicas, bem como configurações institucionais mais amplas. Para tanto, é importante atentar que as instituições se alteram de acordo com o contexto, mas também são restringidas por trajetórias passadas, o que demanda a necessidade de investigações com largas extensões temporais (Skocpol e Pierson, 2002; Thelen, 1999). O ajustamento no tempo (timing) e a dependência da trajetória (path dependence), isto é, as escolhas do presente condicionadas pela herança institucional do passado fazem a diferença na interpretação das transformações das instituições.

No que tange à escolha do método de análise, como o tema demanda foco em todo o arranjo institucional e nas especificidades de cada caso, justifica-se a predominância da adoção da metodologia de estudos de caso, seja ela intensiva em uma única unidade ou o método comparado de poucos países, em detrimento do uso do método quantitativo. Uma estratégia recomendável para abordar problemas de causalidade complexos é o process tracing, que pressupõe a análise de uma série de etapas intermediárias em contexto histórico particular de modo a auxiliar a compreensão da estrutura decisória e seus efeitos.

\subsection{Determinantes da descentralização}

Outro ponto bastante comum na literatura envolve a questão dos determinantes da descentralização. Os analistas vêm se debruçando sobre esse tema de modo a explicar as razões do sucesso ou fracasso das políticas descentralizadas. Em suma, os resultados revelam contrastes marcantes, mas convergem para a percepção de que a implementação efetiva carece da criação de uma estrutura de incentivos e constrangimentos que induza a participação dos governos subnacionais dentro de um processo de negociação e adesão voluntária (Bossert, 1996; Faguet, 1997; Arretche, 2003; Nelson, 2004). Kaufman e Nelson (2004:506) reforçam o argumento:

Incentivos financeiros ligados a requerimentos da reforma são os principais instrumentos dos reformistas para alterar o comportamento em sistemas descentralizados. No Brasil, [...] o desenho das transferências condicionadas em medidas específicas desempenhou um papel central. No longo prazo, incentivos financeiros acompanhados de monitoramento próximo podem ter efeitos poderosos. 
No entanto, boa parte dos estudos enfatiza que para melhor compreender esses processos é essencial não apenas observar o desenho da política pública, mas sim começar a partir das escolhas e instituições políticas que moldam as opções de formulação e implementação, como também antecedentes e fatores conjunturais que moldam a amplitude e os constrangimentos políticos das decisões.

O trabalho seminal de Marta Arretche (2000) ${ }^{3}$ traça uma análise compreensiva dos fatores que influenciam o grau de descentralização de determinadas políticas sociais no âmbito de cinco estados brasileiros. Para tanto, a autora considera três variáveis de tipo institucional: o legado das políticas prévias, as regras constitucionais que normatizam a oferta de bens e serviços e a engenharia operacional inerente à prestação, assim como variáveis de ação política e fatores estruturais (condições econômicas e administrativas). Como resultado, Arretche retrata que o processo de implementação da descentralização no Brasil não foi espontâneo e nem homogêneo. Trata-se de um processo com diferentes resultados, mas que é possível compreender sua lógica, como fica evidente no trecho a seguir:

Em estados federativos, a assunção de atribuições de gestão em políticas públicas depende da decisão soberana dos governos locais — salvo expressas imposições constitucionais e dado que esta decisão é resultado de um cálculo destas administrações quanto aos custos e benefícios nela implicados, a extensão da descentralização depende, em grande parte, da estrutura de incentivos associada à política particular. Essa estrutura associada a requisitos postos pela engenharia operacional de cada política, pelas regras constitucionais que normatizam sua oferta e pelo legado das políticas prévias - que varia de acordo com a área - constituem elementos importantes da decisão local pela assunção de competências de gestão de políticas públicas. (Arretche, 2000:57)

De fato, a literatura converge para o argumento de que a estratégia de adesão dos municípios é um aspecto necessário para o sucesso da descentralização; todavia, as experiências das políticas sociais no Brasil comprovam que ele não é suficiente. Embora a qualidade da implementação da política depen-

\footnotetext{
${ }^{3}$ O livro Estado federativo e políticas sociais: determinantes da descentralização, escrito a partir de sua tese de doutorado, analisa o grau de descentralização de acordo com indicadores e critérios que revelam se um dado nível de governo está institucionalmente comprometido com o exercício de determinadas funções de gestão.
} 
da dos incentivos e do controle aos quais os governos locais são submetidos, não existe obrigatoriedade por parte destes últimos na provisão de serviços em patamares equitativos e eficientes, tendo em vista a autonomia que os municípios gozam. O que envolve outra questão: quais são os condicionantes do desempenho local? Em outras palavras, dentro de uma estratégia de descentralização única que vise maximizar o impacto de fatores apoiadores e ao mesmo tempo minimizar custos, o que pode explicar a variação nos resultados entre governos subnacionais?

Apesar de pouco abordada (Bossert, 1996; Collins, 1996; Peterson, 1995), essa análise é fundamental, dada a estrutura federativa brasileira. O princípio teórico dessa abordagem nos remete à compreensão do comportamento dos atores envolvidos e dilemas de ação coletiva, requerendo análises para além da ótica econômica e administrativa, envolvendo a dimensão políti$\mathrm{ca}$ /institucional. Assim, as pesquisas podem pautar-se na vertente da escolha racional, pois englobam questões sobre a forma como os autores lidam com incentivos no momento da tomada de decisões, comportamento estratégico de diferentes indivíduos e seus impactos sobre os resultados coletivos (Weingast, 1998; Diermeier e Krehbiel, 2003; Shepsle, 2005).

As instituições surgem e se tornam importantes na medida em que a cooperação entre os indivíduos nem sempre é bem-sucedida, isto é, quando os ambientes de jogos repetitivos não são suficientes para consolidar a cooperação de longo prazo. O objeto central de análise da escolha racional é a ação individual, seja de um político, associação ou unidade governamental, dentro de uma estrutura institucional que condiciona os incentivos e constrangimentos. A premissa é que o indivíduo se comporta de modo racional, isto é, toma decisões com base na razão num contexto estratégico, considerando o comportamento dos demais atores (McCubbins e Thies, 1996). Numa perspectiva mais compreensiva, acadêmicos desenvolveram o denominado modelo de análise e desenvolvimento institucional (Institutional Analysis and Development Framework $)^{4}$ que, em termos gerais, indica que a abordagem dos processos e resultados das políticas públicas são afetados, em diferentes graus, por variáveis externas ao indivíduo. São elas: atributos do mundo físico; atributos da comunidade na qual os atores estão inseridos; regras que criam incentivos e constrangimentos a certas ações; e interações com outros indivíduos (Ostrom et al., 1994).

\footnotetext{
${ }^{4}$ Elaborado por Elionor Ostrom e outros acadêmicos associados ao workshop em Teoria e Análise Política da Universidade de Indiana, Estados Unidos.
} 
De acordo com essa linha, a expectativa é que os fatores condicionantes da adesão e empenho dos municípios às políticas importantes para o cálculo de custo-benefício dos tomadores de decisão envolvam fatores relativos aos aspectos estruturais das municipalidades, ao conjunto de instituições inerentes e à conjuntura política/eleitoral.

Quanto aos primeiros, é notório que características econômicas e administrativas das prefeituras tendem a afetar sua capacidade de implementação de um programa. Governos com mais recursos podem desenvolver novas funções e até mesmo empreender inovações que complementem as ações do governo central (Cheema e Rondinelli, 1983; Nelson, 2004). O caso brasileiro não é diferente. A disparidade quanto às capacidades financeiras dos pequenos municípios, à deficiência de recursos humanos e à estrutura física para gerir as políticas sociais é também considerada obstáculo para a consolidação da descentralização no país. Abrucio (2006) salienta que o problema é ainda agravado em função da insuficiência arrecadatória de muitas municipalidades, como exposto no trecho a seguir:

A disparidade de condições econômicas é reforçada, ademais, pela existência de um contingente enorme de municípios pequenos, com pouca capacidade de sobreviver apenas com recursos próprios [...] A pouca capacidade tributária dos municípios brasileiros é ainda maior do ponto de vista comparado, além da máquina administrativa na maioria dos casos precária. (Abrucio, 2006:97)

Além disso, as atenções se voltam para os efeitos dos incentivos e constrangimentos ao comportamento dos atores políticos dentro da lógica de racionalidade. A adesão, empenho e comprometimento do gestor local estão diretamente relacionados às suas escolhas estratégicas visando, em última instância, à sobrevivência política. Essas escolhas, por sua vez, são condicionadas, em grande parte, aos estímulos a que eles estão sujeitos no âmbito das instituições políticas vigentes (Arretche, 2003). Nessa perspectiva, a transferência de responsabilidades muda os incentivos e constrangimentos dos atores políticos locais, na medida em que eles passam a ter suas ações relativas a determinada política pública avaliadas por seus eleitores. Espera-se que em sistemas políticos mais competitivos e com maior participação política e social os gestores locais sejam mais propensos a adotar um comportamento responsável em relação à política pública.

Faguet (1997), entretanto, ressalta que esse cenário somente é possível com a provisão de condições mínimas, a saber: sistema político justo e aberto; transparência na política local e nas questões financeiras do governo; coesão 
e organização social; e governo central como um administrador neutro. Do mesmo modo, Kaufman e Nelson (2004:516) argumentam que: "A competição eleitoral e sistemas democráticos mais abertos raramente geram de modo direto reformas nos setores sociais, mas criam clima político mais receptivo para tal".

Finalmente, cabe ressaltar que as opções metodológicas dessas pesquisas podem variar entre estudo de caso focado e pesquisa quantitativa, especialmente, com uso da técnica de regressão múltipla. Apesar das dificuldades de atingir certeza absoluta da inferência causal, o método quantitativo com "n" suficiente em relação ao número de parâmetros exploratórios estimados tem como vantagem a capacidade de ampliar a validade externa da pesquisa, ou seja, prover generalizações mais amplas e válidas.

\subsection{Isomorfismo em processos de descentralização}

O terceiro e último tema envolve a análise das estratégias de descentralização de políticas públicas em uma perspectiva do isomorfismo institucional, conceito difundido por DiMaggio e Powell (1991), que retrata a tendência das organizações de responderem de forma semelhante quando se encontram em ambientes restritivos em comum. Tal conceito é identificado com a vertente sociológica ou organizacional do neoinstitucionalismo que, de modo geral, preconiza que as preferências e motivações individuais assim como o cálculo de custos e benefícios políticos são menos importantes do que tradições históricas que eles recordam e interpretam dentro de uma complexidade de regras. Dessa forma, os indivíduos atuam nas instituições com base no cálculo de identidade e de adequação (appropriateness). Em outras palavras, a lógica se baseia na ideia de que a vida institucional é organizada por um conjunto de papéis, procedimentos operacionais padrão, práticas, memórias e identidades compartilhadas e previamente dadas (March e Olsen, 1989).

Se, por um lado, a vertente se assemelha à escolha racional na medida em que entende as instituições como fatores de diminuição de incerteza e promotores de equilíbrio da ação coletiva, por outro, os organizacionais divergem drasticamente em relação à formulação da preferência individual. Rothstein (1998) argumenta que, enquanto a primeira subestima o papel da socialização e não explica de onde as preferências se originam, a segunda superdimensiona os efeitos culturais e sociais, e também não expõe argumentos consistentes de como coexistem preferências distintas de atores dentro dos mesmos ambientes institucionais. 
Dentro do neoinstitucionalismo sociológico, o isomorfismo, segundo DiMaggio e Powell (1991), seria o conceito que melhor caracteriza o processo de homogeneização da conduta das organizações. Ele pode ser fruto de três mecanismos: coercitivo, resultado de pressões formais e informais provenientes de outras organizações hierarquicamente superiores; mimético, quando se lida com problemas de causas ambíguas e soluções não claras nas quais a imitação pode ser a resposta para a incerteza e busca de legitimação e/ou sucesso; e normativo, quando surge da profissionalização do quadro funcional e das redes profissionais.

Portanto, a abordagem do isomorfismo institucional poderia ser utilizada na análise da proliferação, em diversos países e áreas de políticas públicas, das estratégias de indução à participação dos governos subnacionais pautada em apoio técnico e financeiro por parte dos governos centrais. Conforme já discernido, elas são consideradas aspectos fundamentais para o sucesso da descentralização. Diante desse consenso nas experiências latino-americanas e no Brasil, a criação de estrutura de incentivos à cooperação tem se mostrado prática comum, sendo os modelos de implementação das políticas de saúde e educação os exemplos clássicos.

Essa reprodução de experiências semelhantes pode ser analisada tanto do ponto de vista do isomorfismo mimético quanto do normativo. No primeiro, o comportamento mimético se apresenta como resposta dos governos a incertezas em relação aos resultados das políticas e às pressões internas e externas por melhorias na qualidade da prestação dos serviços públicos, o que induz a adoção de iniciativas já conhecidas e com resultados positivos.

Sob a ótica normativa, boa parte do consenso acerca das vantagens da descentralização pode ser, em grande medida, considerada consequência da profissionalização dos funcionários e da formação de redes em defesa dessa estratégia. Por outro lado, o mecanismo de isomorfismo coercitivo tem pouco a agregar na análise dessas questões, uma vez que o processo de descentralização intergovernamental, geralmente, envolve mais o princípio da autonomia do que relações de dependência.

Esse tipo de abordagem se mostra relevante não apenas como ferramenta analítica na compreensão da proliferação de estratégias homogêneas de descentralização, mas também como maneira de realçar seus problemas inerentes. A descentralização, como já mencionado anteriormente, pode implicar muitos riscos. Na América Latina, por exemplo, Smoke, Gómez e Peterson (2006) argumentam que prevalecem governos subnacionais não preparados para lidar com as novas funções, o que eles denominam descentralização precoce. Dessa forma, a simples e pura imitação de estratégias bem-sucedidas que 
não consideram as particularidades das relações federativas, especificidades da política e, principalmente, a disparidade entre regiões, estados e municípios no tocante à estrutura administrativa e financeira, pode trazer mais consequências negativas do que propriamente efeitos positivos.

Mesmo na análise do caso brasileiro, a preocupação com os efeitos colaterais das estratégias uniformes de descentralização tem ocupado espaço na literatura (Abrucio, 2005; Farah e Jaco, 2000; Melo, 1996). Em síntese, o foco na equidade e eficiência na prestação dos serviços pautou a implementação das políticas sociais após a Constituição de 1988. Entretanto, o modelo de federalismo fiscal ainda mantém grandes distorções, desigualdades e iniquidades que são refletidas nas capacidades técnicas e operacionais dos governos. Sem dúvida, muitos avanços ocorreram, principalmente, na gestão e nos indicadores de áreas como saúde, educação e combate à pobreza; porém, em outros setores como habitação e saneamento, os resultados da descentralização são bem menos expressivos. Dessa forma, uma questão que merece pesquisa futura é: os esforços pautados em estratégias isomórficas com critério único para um conjunto heterogêneo de municípios, efetivamente, alteram as desigualdades na estrutura de gestão existentes entre os municípios do país?

Do ponto de vista metodológico, a abordagem requer um enfoque nas particularidades do objeto de estudo, o que tende a favorecer a adoção de metodologia qualitativa, mais especificamente, estudos de casos comparados. Nessa situação, o uso apenas de técnicas estatísticas pode prejudicar a captura de especificidades na análise de cada processo de isomorfismo institucional.

\section{Considerações finais}

O presente artigo teve como objetivo principal ampliar o debate sobre as possibilidades do estudo de descentralização das políticas públicas, ressaltando o quanto os pressupostos das versões do neoinstitucionalismo podem ser úteis como ferramentas analíticas às pesquisas que almejam investigar de forma compreensiva essa complexa e mutante temática.

Nesse sentido, Diermeier e Krehbiel (2003) afirmam que a teoria neoinstitucional pode exercer duas funções não excludentes: uma positiva e outra normativa. A primeira contribui com vistas a ampliar o conhecimento de como as instituições afetam o comportamento político e os resultados das políticas. Com base nesse conhecimento, é possível formular proposições de ordem normativa no sentido de aperfeiçoar instituições de forma a criar incentivos favo- 
ráveis ao comportamento desejado, tanto em processos de reforma quanto de implementação das políticas públicas.

No entanto, a maioria dos estudos de descentralização carece dessa fundamentação de natureza positiva, como a dificuldade dos analistas em apresentar inferências consistentes acerca do relacionamento causal entre descentralização e muitos de seus benefícios propagados. Tais limitações, por sua vez, implicam fragilidade nas análises e conclusões, como também impedem a elaboração de proposições normativas válidas.

O debate atual não é se a descentralização é "boa" ou "ruim", uma vez que ela é uma realidade na administração pública em todo o mundo. A questão ganha ainda mais respaldo no caso brasileiro, na medida em que a estrutura do federalismo e a heterogeneidade dos municípios requerem análises multivariadas e metodologicamente válidas das relações intergovernamentais.

Embora reiterada durante o artigo a relevância do olhar institucional, a proposta não é restringir o escopo analítico, ao contrário, procurou-se apresentar ferramentas e problemas que podem enriquecer ainda mais o debate sobre descentralização. Cabe aos pesquisadores, no momento de traçar suas estratégias analíticas, considerar os prós e contras da opção metodológica e o arcabouço teórico que melhor se ajustam na abordagem do objeto de estudo selecionado. E, assim, agregar contribuições à compreensão do processo decisório, seus impactos e resultados subjacentes à implementação de política pública descentralizada.

\section{Referências}

ABRUCIO, Fernando. A coordenação federativa no Brasil: a experiência do período FHC e os desafios do governo Lula. Revista de Sociologia e Política, Curitiba, n. 24, p. 41-67, 2005.

ABRUCIO, Fernando. Para além da descentralização: os desafios da coordenação federativa no Brasil. In: FLEURY, Sônia (Org.). Democracia, descentralização e desenvolvimento: Brasil e Espanha. 1. ed. Rio de Janeiro: FGV, p. 77-125, 2006.

AFFONSO, Rui; SILVA, Pedro (Org.). Descentralização e políticas sociais. São Paulo: Fundap, 1996.

ALMEIDA, Maria Hermínia Tavares. Federalismo e políticas sociais. In: AFFONSO, Rui; SILVA, Pedro (Org.). Descentralização e políticas Sociais. São Paulo: Fundap, 1996. 
ALMEIDA, Maria Hermínia Tavares. Federalismo e proteção social: a experiência brasileira em perspectiva comparada. In: Seminário Pacto Federativo e Guerra Fiscal no Brasil. São Paulo: FGV, 2000.

ALMEIDA, Maria Hermínia Tavares. Recentralizando a Federação? Revista de Sociologia Política, n. 24, p. 29-40, jun. 2005.

ARRETCHE, Marta. Estado federativo e políticas sociais: determinantes da descentralização. São Paulo: Fapesp, 2000.

ARRETCHE, Marta. Federalism and place-equality policies: a case study of policy design and outputs. EUI Working Papers, SPS 2, 2009.

ARRETCHE, Marta. Federalismo e políticas sociais no Brasil: problemas de coordenação e autonomia. São Paulo em Perspectiva, v. 2, n. 18, p. 17-26, 2004.

ARRETCHE, Marta. Financiamento federal e gestão local de políticas sociais: o difícil equilíbrio entre regulação, responsabilidade e autonomia. Ciência \& Saúde Coletiva, v. 2, n. 8, p. 331-345, 2003.

BOSSERT, Thomas. Decentralization. In: JANOVSKY, K. (Ed.). Health policy and systems development an agenda for research. Geneva: World Health Organization, 1996. p. 147-160.

CHEEMA, G. Shabbir; RONDINELLI, Dennis (Ed.). Decentralization and development: policy implementation in developing countries. Beverly Hills: Sage Publications, 1983.

CHEEMA, G. Shabbir; RONDINELLI, Dennis. Decentralizing governance: emerging concepts and practices. Brookings Institution Press, 2007.

COHEN, John; PETERSON, Stephen. Methodological issues in the analysis of decentralization. Development Discussion Paper, Cambridge, n. 555, 1996.

COLLINS, Charles. Decentralization. In: JANOVSKY, Katja (Ed.). Health policy and systems development: an agenda for research. Geneva: World Health Organization, 1996. p. 161-178.

DIERMEIER, Daniel; KREHBIEL, Keith. Institutionalism as a methodology. Journal of Theoretical Politics, n. 15, p. 123-145, 2003.

DIMAGGIO, Paul; POWELL, Walter (Org.). The new institutionalism in organizational analysis. Chicago: University of Chicago Press, 1991.

FAGUET, Jean-Paul. Decentralization and local government performance. Technical Consultation on Decentralization. Rome: FAO, 1997. 
FALLETI, Tulia. Efeitos da descentralização nas relações intergovernamentais: o Brasil em perspectiva comparada. Sociologias, Porto Alegre, ano 8, n. 16, p. 46-85, jul./dez. 2006.

FARAH, Marta Ferreira Santos; JACO, Pedro. Governos locais e cooperação inter e intragovernamental no Brasil. In: FARAH, Marta; BARBOSA, Hélio Batista (Org.). Novas experiências de gestão pública e cidadania. São Paulo: FGV, 2000.

FRANZESE, Cibele; ABRUCIO, Fernando. A combinação entre federalismo e as políticas públicas no pós-1988: os resultados nas áreas de saúde, assistência social e educação. In: ROCHA, M.C.G. da (Org.). Reflexões para ibero-América: avaliação de programas sociais. Brasília: Enap, 2009. p. 25-42.

GONZALEZ, Lucas. Political power, fiscal crises, and decentralization in Latin America: federal countries in comparative perspective (and some contrasts with unitary cases). Publius: The Journal of Federalism, p. 1-37, 2008.

HALL, Peter; TAYLOR, Rosemary. As três versões do neoinstitucionalismo. Lua Nova, São Paulo, n. 58, p. 193-223, 2003.

IMMERGUT, Ellen. As regras do jogo: a lógica da política de saúde na França, na Suíça e na Suécia. Revista Brasileira de Ciências Sociais, v. 30, n. 11, p. 139-163, 1996.

IMMERGUT, Ellen. Institutional constraints on policy. In: MORAN, Michael; REIN, Martin; GOODIN, Robert (Ed.). The Oxford handbook of public policy. Oxford: Oxford University Press, 2006. p. 557-571.

KAUFMAN, Robert; NELSON, Joan M. Crucial needs, weak incentives: social sector reform, democratization, and globalization in Latin America. Washington: Wilson Center Press, 2004.

MARCH, James; OLSEN, Johan. Rediscovering institutions: the organizational basis of politics. New York: The Free Press, 1989. p. 21-38.

MCCUBBINS, Mathew; THIES, Michael. Rationality and the foundations of positive political theory. Rebaiasan [Leviathan], n. 19, p. 7-32, Autumn 1996.

MELO, Marcus André. Federalismo e política social: as vicissitudes da descentralização. In: MELO, Norma L.; LEAL, Suely M.R. (Org.). Relação público-privado: do local ao global. Recife: UDUFPE, 1996.

MELO, Norma L.; LEAL, Suely M.R. O sucesso inesperado das reformas de segunda geração: federalismo, reformas constitucionais e política social. DADOS - Revista de Ciências Sociais, Rio de Janeiro, v. 48, n. 4, 2005. 
MONTERO, Alfredo; SAMUELS, David (Ed.). Decentralization and democracy in Latin America. Notre Dame: University of Notre Dame Press, 2004.

MORRIS, Arthur; LOWDER, Stella (Ed.). Decentralization in Latin America: an evaluation. New York: Praeger, 1992.

NELSON, Joan M. The politics of health sector reform: cross-national comparisons. In: KAUFMAN, Robert; NELSON, Joan M. (Ed.). Crucial needs, weak incentives: social sector reform, democratization, and globalization in Latin America. Washington: Wilson Center Press, 2004. cap. 2.

NORTH, Douglas. Institutions, institutional change, and economic performance. New York: Cambridge University Press, 1990.

OSTROM, Elinor; GARDNER, Roy; WALKER, James. Rules, games, and common pool resources. Ann Arbor: The University of Michigan Press, 1994.

OSTROM, Elinor. Institutional rational choice: an assessment of the IAD framework. In: SABATIER, Paul (Ed.). Theories of the policy process. Boulder, CO: Westview Press, 1999.

PETERSON, Paul. The price of federalism. The Tweentieth Century Fund. Nova York: Peterson, 1995.

PRUD'HOMME, Remy. The dangers of decentralization. World Bank Research Observer, v. 10, n. 2, p. 201, 1995.

RHODES, R.A.W. The institutional approach. In: MARSH, David; STROKER, Gerry (Ed.). Theory and methods in political science. Second edition, comprehensively revised and updated. London: Palgrave Macmillan, 2002. p. 42-57.

ROTHSTEIN, Bo. Political institutions: an overview. In: GOODIN, R.E.; KLINGERMANN, H. Political science: the discipline, new handbook of political science. Oxford: Oxford University Press, 1998. p. 133-167.

SAMUELS, David. The political logic of decentralization in Brazil. In: MONTERO, Alfredo; SAMUELS, David (Ed.). Decentralization and democracy in Latin America. Notre Dame: University of Notre Dame Press, 2004. p. 67-93.

SCHMIDT, Vivien. Give peace a chance: reconciling the four (not three) new institutionalisms in political science. Presented at Annual Meeting Am. Polit. Sci. Assoc. Philadelphia, 2006.

SHEPSLE, Kenneth. Rational choice institutionalism. In: BINDER, S.; RHODES, R.; ROCKMAN, B. (Ed.). Handbook of political institutions. Oxford: Oxford University Press, 2005. 
SKOCPOL, Theda; PIERSON, Paul. Historical institutionalism in contemporary political science. In: KATZNELSON, Ira; MILNER, Helen V. (Ed.). Political science: state of the discipline. Nova York: W.W. Norton, 2002.

SMOKE, Paul; GÓMEZ, Eduardo J.; PETERSON, George E. Decentralization in Asia and Latin America: towards a comparative interdisciplinary perspective. Northampton: Edward Elgar, 2006.

SMOKE, Paul; OLOWU, Dele. Determinants of success in african local governments: an overview. Public Administration and Development, v. 12, n. 1, p. 1-17, 1992.

SMOKE, Paul; OLOWU, Dele. Successful African local government: methodological and conceptual issues reconsidered. Public Administration and Development, v. 13, n. 5, p. 507-514, 1993.

SOUZA, Celina. Federalismo, desenho constitucional e instituições federativas no Brasil pós-1988. Revista de Sociologia e Política, Curitiba, v. 24, n. 24, p. 105-122, 2005.

STOHR, Walter. Introduction. In: STOHR, Walter; EDRALIN, Josefas; MANI, Devyani (Ed.). New regional development paradigms: decentralization, governance and the new planning for local-level development. Westport, CT: Greenwood Press, 2001.

TENDLER, Judith. Bom governo nos trópicos: uma visão crítica. Rio de Janeiro: Revan, 1998.

THELEN, Kathleen. Historical institutionalism in comparative politics. Annual Review of Political Science, n. 2, p. 369-404, 1999.

THELEN, Kathleen; STEINMO, Sven. Historical institutionalism in comparative politics. In: STEINMO, Sven; THELEN, Kathleen; LONGSTRETH, Frank (Ed.). Structuring politics: historical institutionalism in comparative analysis. Cambridge: Cambridge University Press, 1992. p. 1-32.

WEAVER, Kent; ROCKMAN, Bert (Ed.). Do institutions matter? Washington: Brookings Institution, 1993.

WEINGAST, Barry. Rational choice institutionalism. In: GOODIN, R.; KLINGERMANN, H. Political science: the discipline, a new handbook of political science. Oxford: Oxford University Press, 1998.

WEIR, Margaret; ORLOFF, Ann Shola; SKOCPOL, Theda. The politics of social policy in the United States. Princeton: Princeton University, 1998.

WORLD BANK. Decentralization: what, why and where. Disponivel em: <www1. worldbank.org/publicsector/decentralization/what.htm>. Acesso em: 25 mar. 2010. 